\title{
Canadian Urological Association guideline: Erectile dysfunction
}

Trustin Domes, MD, MEd ${ }^{1}$; Borna Tadayon Najafabadi, MD, $\mathrm{MPH}^{2}$; Matthew Roberts, MD, $\mathrm{MEd}^{3}$; Jeffrey Campbell, $\mathrm{MD}^{4}$; Ryan Flannigan, $\mathrm{MD}^{5}$; Phil Bach, $\mathrm{MD}^{6}$; Premal Patel, $\mathrm{MD}^{7}$; Gavin Langille, $\mathrm{MD}^{8}$; Yonah Krakowsky, $\mathrm{MD}^{9}$; Philippe D. Violette, MD, MSc ${ }^{2,10}$

${ }^{1}$ Division of Urology, Department of Surgery, University of Saskatchewan, Saskatoon, SK, Canada; ${ }^{2}$ Department of Health Research Methods, Evidence and Impact, McMaster University, Hamilton, ON, Canada; ${ }^{3}$ Division of Urology, Department of Surgery, University of Ottawa, Ottawa, ON, Canada; ${ }^{4}$ Division of Urology, Department of Surgery, Western University, London, ON, Canada; ${ }^{5}$ Department of Urological Sciences, University of British Columbia, Vancouver, BC, Canada; ${ }^{6}$ Division of Urology, Department of Surgery, University of Alberta, Edmonton, AB, Canada; ${ }^{7}$ Division of Urology, Department of Surgery, University of Manitoba, Winnipeg, MB, Canada; ${ }^{8}$ Saint John Regional Hospital, Saint John, NB, Canada; ${ }^{9}$ Division of Urology, Women's College Hospital \& Sinai Health System, Department of Surgery, University of Toronto, Toronto, ON, Canada; ${ }^{10}$ Department of Surgery, McMaster University, Hamilton, ON, Canada

Reviewers: Gerald B. Brock, MD; Faysal Yafi, MD

Cite as: Domes T, Najafabadi BT, Roberts M, et al. Canadian Urological Association guideline: Erectile dysfunction. Can Urol Assoc J 2021 August 17; Epub ahead of print. http://dx.doi.org/10.5489/cuaj.7572

Published online August 17, 2021

Corresponding author: Dr. Trustin Domes, Division of Urology, Department of Surgery, University of Saskatchewan, Saskatoon, SK, Canada; trustin.domes@ usask.ca $* * *$

\section{Abstract}

Erectile dysfunction (ED) impacts the wellness and quality of life of millions of Canadians. An evaluation focused on the identification of reversible and irreversible underlying factors is recommended for patients presenting with ED. Through a shared decision-making model framework, the goal of ED treatment is to improve functional outcomes and enhance sexual satisfaction while minimizing adverse effects associated with treatment. Given that ED is assessed and treated by multiple different types of health practitioners, the purpose of this guideline is to provide the best available evidence to facilitate care delivery through a Canadian lens. After a narrative review of ED assessment and treatment for general 
readership, five key clinical questions relating to priority areas of ED are assessed using the GRADE and Evidence to Decision making frameworks.

\section{Introduction}

Erectile dysfunction (ED) is the inability to achieve or maintain an erection sufficient for satisfactory sexual performance. Penile erection requires a complex integration between vascular, neural and endocrine systems leading to adequate arterial dilatation, trabecular smooth muscle relaxation, and activation of the corporal veno-occlusive mechanism ${ }^{1}$.

ED is highly prevalent, with both the Canadian Study of Erectile Dysfunction ${ }^{2}$ and the Massachusetts Male Aging Study (MMAS) ${ }^{3}$ reporting high rates of men experiencing ED with a higher prevalence and severity associated with aging. For example, in the MMAS approximately $40 \%$ of men in their 40 's experienced ED of varying degrees of severity and the prevalence of ED increases about $10 \%$ per decade. Additionally, as a man ages, the proportion of men with a higher severity of ED increases. In the MMAS, the prevalence of severe ED tripled from 5\% in men in their 40's to $15 \%$ in men in their 70 's.

ED can be categorized as organic, psychogenic or mixed based on the patient's history and examination findings. Organic ED is typically classified by its underlying pathophysiological mechanism(s) which include vasculogenic (most common), neurogenic, structural, and hormonal causes. ${ }^{1}$ Psychogenic ED can be generalized or situational and may be related to a history of psychosocial stress, performance anxiety and mental illness ${ }^{4}$.

There are many modifiable and non-modifiable risk factors associated with primarily vasculogenic ED including advancing age, diabetes mellitus, dyslipidemia, hypertension, obesity, metabolic syndrome, sedentary lifestyle, and smoking. ${ }^{5-7}$ There is a large body of evidence suggesting that ED and cardiovascular and cerebrovascular diseases share the same risk factor profile and that ED may serve as an early warning sign for the future development of vascular events in some populations ${ }^{5,8}$. In spite of this established link, some studies have demonstrated that ED is not an independent risk predictor of future vascular events and that established risk predictors, such as the Framingham risk score, are superior ${ }^{9,10}$. Therefore, it remains controversial whether a diagnosis of ED alone should initiate a more thorough cardiovascular evaluation. Patient factors such as age, ED severity and duration and the presence of other cardiovascular risk factors should guide clinicians when deciding if further investigations or optimization of cardiovascular health is required, in collaboration with other health care providers. ${ }^{5,8,11-13}$.

ED is common after trauma (pelvic trauma and penile fracture), surgery (pelvic, penile and urethral) and radiation therapy ${ }^{14-18}$. Specifically, the Prostate Cancer Outcome Study ${ }^{19}$ reported $78.8 \%$ of post-prostatectomy patients not having erections firm enough for intercourse two years after surgery compared to $60.8 \%$ of men having ED two years following 
prostate radiotherapy. After 15 years from the time of treatment, the prevalence of ED increases further to $87 \%$ post-prostatectomy and $94 \%$ post-radiiotherapy. ${ }^{19} \mathrm{ED}$ is also frequently associated with other urological conditions such as lower urinary tract symptoms/benign prostatic hyperplasia ${ }^{20}$ and chronic prostatitis/chronic pelvic pain syndrome ${ }^{21}$.

The impacts of ED go beyond the physical loss of function and the inability of having sexual intercourse. ED has a significant impact on the psychosocial health, wellbeing and quality life for both the patient and their partner ${ }^{22,23}$ and can negatively impact relationships ${ }^{24}$. It is critical for the clinician to be aware of these potential negative effects on the couple. Including the partner during ED assessment and treatment has been shown to improve patient outcomes $^{25,26}$.

\section{Methods}

A guideline panel of 10 members including male sexual health, urology, and guideline methodology experts was established. The goal of the panel was to address relevant and priority issues and questions surrounding current ED practice and to produce an impactful document for learners and practitioners.

The guideline panel met and generated a broad list of topics and clinical questions relating to ED. In addition, each panel member selected and surveyed two community urologists practicing in their region in order to generate a second list of clinical questions that were felt to be relevant to the practice of a general urologist. Thirty questions were compiled and the panel selected the five most important questions through individual ratings based on perceived topic priority, identified practice variation and expected feasibility of answering the question (Appendix). These 5 questions were addressed systematically using the Grading of Recommendations Assessment, Development and Evaluation (GRADE) approach and the Evidence to Decision (EtD) framework ${ }^{27,28}$.

The GRADE approach enabled the panel to appreciate the certainty in the evidence for each outcome, and overall, as very low, low, moderate, or high ${ }^{29,30}$. The EtD framework assisted the panel in making clinical recommendations by considering desirable effects, undesirable effects, balance of the effects (net benefit), certainty in estimates of effect, patients' values and preferences, resources required, cost-effectiveness, equity, feasibility, and acceptability $^{31}$. Summary of Findings (SoF) and EtD framework tables using the GRADEpro GTD application ${ }^{32,33}$ are available in the Appendix.

The panel chose improvements in erectile function (measured by the International Index of Erectile Function (IIEF)-EF score ${ }^{34}$ ) and quality of life as critical outcomes, and adverse events as an important outcome, to be collected during the literature review. The panel used the generally accepted minimal clinically important difference (MCID) of 4 in the IIEF-EF score as a significant improvement in erectile function, however the panel recognizes 
the limitation that the MCID varies based on the baseline severity of ED (mild: 2; moderate: 5; severe: 7). ${ }^{35}$.

Effect estimates were derived from studies contained in existing systematic reviews that addressed the five chosen clinical questions and by reproducing some of the review stages to ensure the most accurate effect estimates were calculated. These review steps included appraisal of the reviews, review of additional literature to locate any missing major trials, determining the risk of bias in the included studies, and performing the meta-analyses again.

Interpreting recommendations in the GRADE framework emphasizes the role of shared decision-making and patient values and preferences. In this framework, recommendations can be for or against and strong or conditional. A strong recommendation indicates that the panel believes that a significant majority of patients would choose the recommended course of action when aware of the available evidence. A conditional recommendation implies that the panel believes that most patients would want the recommended course of action, however a substantial proportion would not. For clinicians, this means that when a weak recommendation is made the "best" course of action will rely on elucidating patient values and preferences in a shared decision-making process.

\section{Background and narrative overview of ED}

\section{Patient assessment}

The cornerstone of the assessment of patients with ED is a detailed history and physical exam. Screening laboratory testing to rule out associated conditions should be considered for patients presenting with ED, depending on the clinical context. Specialized tests, including imaging, are of limited value and are not recommended except in special circumstances.

\section{History}

A detailed history should include medical and psychological co-morbidities, medications, substance use history (tobacco, alcohol, drugs), surgical and pelvic radiation history, a history of pelvic trauma, and previous treatments for sexual dysfunction. A detailed psychosocial and sexual history is key to a comprehensive assessment. While the underlying cause of ED is often multifactorial, key questions related to psychosocial factors and sexual history can point towards psychogenic and situational factors contributing to sexual dysfunction (Table 1). It has been hypothesized that excessive pornography use may contribute to sexual dysfunction during partnered sex ${ }^{36}$, especially in younger patients with ED. However, this association is not clearly demonstrated in the empirical literature and requires further study ${ }^{37,38}$. Comorbid sexual conditions such as premature ejaculation (PE), anorgasmia, low libido, and Peyronie's Disease (PD) should be identified in the initial assessment of any patients with ED, as the presence of these comorbid conditions will impact further assessment and management of ED. 
Assessment tools

Validated questionnaires and assessment tools (Table 2) can be useful in the initial diagnosis and follow-up of ED patients, especially when evaluating a patient's response to treatment. While these assessment tools do not replace a detailed history and physical exam, they are cost-effective and non-threatening for patients to complete ${ }^{39}$, however these tools have varying degrees of utility in clinical practice. These assessment tools were originally validated in the heterosexual population, however the IIEF has also been shown to be efficacious in the men who have sex with men (MSM) population. ${ }^{40}$

\section{Physical examination}

Physical examination is a helpful adjunct to assess a patient's overall body habitus, level of virilization and genital anatomy to identify any comorbid medical and/or sexual conditions ${ }^{41}$. Table 3 summarizes the key features of the physical examination for patients with ED.

\section{Laboratory testing}

In patients with either suspected vasculogenic or idiopathic ED, a baseline hemoglobin A1C, fasting glucose and lipid profile should be considered to rule out occult diabetes and dyslipidemia. Patients with symptoms associated with testosterone deficiency or failure of phosphodiesterase type-5 inhibitors (PDE5is) should consider having a morning serum total testosterone level drawn ${ }^{41}$.

\section{Specialized testing}

Specialized testing, including nocturnal penile tumescence (NPT) and penile duplex ultrasound (PDU), is rarely required in the routine assessment of patients with ED. These tests can be used to differentiate between organic and non-organic causes of ED when the patient's history is conflicting and in medico-legal cases. NPT estimates nocturnal penile rigidity ${ }^{42}$ and PDU measures arterial inflow (to assess arterial insufficiency) and venous outflow (to assess for venous leak) after the injection of a vasoactive substance ${ }^{43}$. Both tests provide little practical information beyond what can be obtained from a detailed history and should only be obtained in limited situations by sub-specialists in sexual medicine.

\section{Treatment options}

\section{Overview}

In Canada, primary care providers (PCPs) appropriately identify, investigate and initiate firstline treatments in the vast majority of patients with ED. In the contemporary model of ED care patients may be referred to urologists after failure of first-line therapy as second-line therapies may be outside the practice pattern of $\mathrm{PCPs}^{44}$. A patient-centred, shared decisionmaking model is advocated when discussing treatment options with the patient and their 
partner. Management of ED typically follows a stepwise progression from conservative measures to first-line phosphodiesterase type-5 inhibitors (PDE5is) through to second- and third-line treatment options, however specific patient factors and expectations may influence treatment decisions and the usual stepwise progression of treatment options (Fig 1).

\section{Conservative treatment options}

Conservative measures should be offered and continuously addressed with all patients with ED, especially if comorbidities or lifestyle habits are negatively impacting erectile function ${ }^{45}$. These measures include exercise/physical activity ${ }^{46}$, smoking cessation ${ }^{47}$, reducing alcohol ${ }^{47}$ and cannabis consumption ${ }^{48}$, and dietary changes. Additionally, the nitric oxide synthase substrates L-arginine and citrulline have been evaluated in limited studies ${ }^{49-51}$, but further confirmatory work is required prior to recommending their use in ED at this time.

Clinicians should consider early referral for sexual counselling for patients

experiencing ED, especially when there is concern for a psychogenic component ${ }^{4,52,53}$. Sexual counselling may be a helpful adjunct to medical management and may improve relationship satisfaction and overall sexual functioning ${ }^{54}$.

Low-intensity shock wave therapy (Li-SWT)

Low intensity shock wave therapy (Li-SWT) is a treatment option proposed for patients with mild to moderate ED. Li-SWT is administered with a wand-like device delivering low intensity shockwaves to different areas of the penis in multiple sessions. Li-SWT is hypothesized to work by inducing angiogenesis through growth factor activation ${ }^{55}$ and inducing nerve regeneration ${ }^{56}$, thereby reversing pathophysiological processes to improve erectile function. Although widely offered in numerous centres in Canada, often by nonurologists, Li-SWT is not Health Canada or FDA approved for clinical use for ED. The clinical use of Li-SWT for ED is addressed in the key clinical recommendation section of this guideline.

\section{Phosphodiesterase type-5 inhibitors (PDE5is)}

Phosphodiesterase type-5 inhibitors (PDE5is) are a class of oral agents that facilitate a penile erection by promoting vascular and cavernosal smooth muscle relaxation in response to sexual stimulation ${ }^{57}$. The PDE5is approved by Health Canada include sildenafil, tadalafil and vardenafil. Each medication has unique pharmacokinetic and pharmacodynamic properties ${ }^{58}$ (see Table 1). Patients initiating PDE5is should be counselled regarding potential side effects including headache, flushing, dyspepsia, and nasal stuffiness which are universal in all three drugs with alterations in colour vision (sildenafil and vardenafil) and myalgias (tadalafil) being more drug-specific ${ }^{58,59}$. Absolute contraindications to PDE5is include intermittent or regular use of nitroglycerin or organic nitrates and hypersensitivity to any component of the 
tablet ${ }^{58}$. Patients with an unsatisfactory response to PDE5is should first be counselled regarding proper use of the medication and may require a potential dose adjustment ${ }^{60}$.

The panel strongly recommends PDE5is as the first line pharmacological treatment for ED given their impressive clinical efficacy and safety profile in a wide range of patients. A comprehensive systematic review by Yuan and colleagues ${ }^{61}$ reports a clinically significant mean improvement in the IIEF-EF score of 6.03 (95\% CI: 5.38, 6.68) for sildenafil (12 RCTs, 3404 patients), 8.07 (95\% CI: 7.18, 8.96) for tadalafil (8 RCTs, 1877 patients) and 7.05 (95\% CI: 5.60, 8.50) for vardenafil (6 RCTs, 1151 patients). These drugs also have a strong safety profile, with the effect estimate for relative risk of serious adverse events being 1.38 (95\% CI: $0.67,2.83$ ) for sildenafil ( $10 \mathrm{RCTs}, 2431$ patients), 1.46 (95\% CI: 0.63, 3.37) for tadalafil (8 RCTs, 1967 patients) and 1.49 (95\% CI: 0.79, 2.83) for vardenafil (10 RCTs, 3628 patients) compared to placebo. Conceptualized another way with considering baseline risks in the included studies, out of 1000 patients taking the drug on average 8 will experience a serious adverse event with sildenafil, 7 with tadalafil and 8 with vardenafil.

\section{Intraurethral alprostadil}

Intraurethral alprostadil, known as MUSE ${ }^{\mathrm{TM}}$ (Medicated Urethral System for Erection), is a second line option for men with ED. It is effective for select patients, but has failed to gain a significant market share due suboptimal efficacy and urethral discomfort ${ }^{62}$. Dose titration with an 'in office' trial is advised to improve success ${ }^{63}$. Since it does not require an injection, some patients prefer it over intracavernosal injection (ICI) ${ }^{64}$.

Vacuum erection pump device (VED)

Vacuum erection pump devices (VED) consist of a cylindrical chamber placed over the penis coupled with a manual or mechanical pump to generate a vacuum. The negative pressure generated promotes blood flow into the penis which is trapped by a constriction ring placed at the base of the penis and can be maintained safely for up to 30 minutes ${ }^{65}$. Given the mechanics involved, VED is considered a more cumbersome and labour-intensive way to achieve an erection. However, $90 \%$ of patients will achieve a functional erection with adequate instruction and practice ${ }^{66}$. VED can be associated with penile numbness, pain, bruising, and painful ejaculation. VED has no absolute contraindications making it a reasonable option for those who cannot tolerate or have contraindications to other medical or surgical options.

\section{Intracavernosal injection (ICI)}

Intracavernosal injection (ICI) was the first pharmacologic treatment available for ED and involves the delivery of vasoactive agents directly into the corpus cavernosum prior to intercourse. Single agent alprostadil has been shown to be highly effective and generally well tolerated, with up to $94 \%$ of patients being able to achieve an erection sufficient for 
intercourse $^{67}$. Side effects include pain at the injection site, penile bruising, penile pain, penile scarring/curvature and priapism. Although not approved by Health Canada, the addition of papaverine and phentolamine to alprostadil, often referred to as "Trimix", has been shown to be even more efficacious than alprostadil monotherapy while maintaining an acceptable side effect profile and less penile pain ${ }^{68}$. Prior to prescribing ICI, patients or their partners need to have the manual dexterity to prepare and perform the injection and a teaching session is advised to ensure proper injection technique and dose titration ${ }^{69}$.

\section{Penile prosthesis}

While not all nonsurgical options need to be attempted prior to considering placement of a penile prosthesis, all nonsurgical options should at least be discussed with the patient prior to considering surgical intervention. There are two types of prosthesis, malleable and inflatable, and both are surgically implanted into the corporal bodies to allow the patient to regain penile rigidity. The presence of clinically significant penile curvature, which may only be evident during activation of the device, should be discussed preoperatively and surgically corrected at the time of device implantation. Satisfaction rates are high for both implant naïve patients and those undergoing surgical revision of an existing device ${ }^{70}$. Patients considering a penile prosthesis need to be aware that postoperative penile length can be negatively affected by corporal fibrosis or previous prostatectomy and the glans will remain flaccid post implant ${ }^{71}$. Mechanical failure does occur with inflatable devices over time, but almost $50 \%$ will still be functional after 20 years of use ${ }^{72}$. Rare but serious late complications include infection or erosion of the device, which in certain cases can lead to refractory and permanent ED.

\section{Clinical recommendations using GRADE}

\section{Summary of recommendations}

\section{Among patients with erectile dysfunction, should daily tadalafil be preferentially prescribed instead of on-demand tadalafil?}

Based on the available evidence, the panel conditionally recommends against preferentially prescribing daily tadalafil instead of on-demand tadalafil for patients presenting with erectile dysfunction. However, certain patient-centered factors may influence what dosing regimen the patient ultimately decides to pursue.

The panel reviewed eight $\mathrm{RCTs}^{73-80}$ comparing improvement in erectile function between on-demand tadalafil $(n=749)$ and daily tadalafil $(n=749)$ over a follow-up period of 8 to 12 weeks. The meta-analysis demonstrates a mean increase in the IIEF-EF score of 0.8 (95\% CI: $-0.32,1.93$ ), favouring daily tadalafil, with a moderate certainty of evidence. This small difference is not clinically significant. Additionally, pooled analyses of 17 on-demand 
and 4 daily tadalafil placebo-controlled trials demonstrated both treatment regimens are similarly efficacious across a broad spectrum of clinical subgroups ${ }^{81}$. Based on RCT data, there is virtually no meaningful difference in side effects or discontinuation rates between either dosing regimen.

Patient-centred factors influencing daily dosing preference

Although treatment efficacy and side effect profiles are very similar between on-demand and daily tadalafil, certain patient-centered factors need to be considered when a decision on dosing frequency is made with the patient. Numerous studies have shown that daily tadalafil increases sexual spontaneity, improves sexual self-confidence and there is less of a concern regarding timing of medication and the associated anticipatory anxiety that can be experienced in some patients taking on-demand tadalafil ${ }^{76,79,82}$. A study by Conaglen and colleagues found that female partners preferred daily dosing compared to on-demand regimens ${ }^{83}$. In patients experiencing co-morbid lower urinary tract symptoms, daily tadalafil $(5 \mathrm{mg})$ is an approved treatment option and has been shown to decrease symptom scores significantly more than on-demand dosing ${ }^{78}$. Additionally, daily tadalafil may be more costeffective than on-demand dosing, depending on the frequency of use and whether a low (2.5 $\mathrm{mg}$ ) or high $(5 \mathrm{mg})$ daily dose regimen is required to achieve an adequate erection.

\section{Among patients with erectile dysfunction, should low-intensity shockwave therapy (Li-SWT) be recommended over no treatment?}

Based on the available evidence, the panel conditionally recommends against low-intensity shockwave treatment (Li-SWT) as a treatment for patients with ED at this time.

The panel reviewed seven $\mathrm{RCTs}^{84-90}$ comparing improvement in erectile function between patients treated with Li-SWT $(n=293)$ or a sham treatment $(n=202)$. The studies had different treatment protocols (shockwave machines, energy levels, duration of treatment and schedule of treatments), various sham treatments, inconsistent follow-up timing, short followup and varying metrics resulting in significant heterogeneity between the studies. Combining the results of all seven RCTs demonstrates a mean increase in the IIEF-EF score of 4.08 (95\% CI: $1.57,6.58$ ) with a very low certainty of evidence, given that three trials ${ }^{84,86,90}$ have a high risk of bias. If these three studies are removed, combining the results of the remaining four studies results in a mean increase in the IIEF-EF score of 2.07 (95\% CI: 0.19,3.96) with a moderate certainty of evidence. Given the quality of the evidence, the panel has more confidence in this latter result, indicating that Li-SWT is unlikely to have a noticeable clinical improvement in erectile function. 
Fojecki and colleagues ${ }^{88}$ collected quality of life data using the Sexual Quality of Life for Men (SQoL-M) tool ${ }^{91}$ in their study of 118 patients. Given the cross-over design, the sham group had received five penile Li-SWT treatments compared to ten in the treatment arm at the 18-week mark when the SQoL-M was re-administered after baseline. The Li-SWT arm scored 2.1 points higher $(95 \%$ CI: $-7.9,12.1)$ than the sham group with a very low certainty of the evidence, indicating no significant improvement in sexual quality of life between ten versus five Li-SWT treatments.

Li-SWT is believed to be a safe procedure with virtually no short-term adverse effects ${ }^{92,93}$ reported, but more research is required to assess the possibility of longer-term adverse effects.

Concerns of introducing Li-SWT into the Canadian healthcare setting

Given the trivial desirable effects on erectile function, the uncertainty regarding the evidence and long-term effects, and concerns regarding cost-effectiveness, equity and feasibility to deliver this treatment in the Canadian health care setting, the panel decided to conditionally recommend against Li-SWT for the treatment of ED at this time. Further adequately powered RCTs focusing on patient safety and more efforts to define the dose, type of machine and patient populations most likely to benefit is required. Additionally, establishing longer-term clinical efficacy using validated and standardized protocols need to be conducted before this modality should be offered for men with ED outside of a clinical trial.

\section{Among patients with erectile dysfunction and hypogonadism, should testosterone replacement be used as monotherapy compared to no treatment?}

Based on the available evidence, the panel conditionally recommends against using testosterone as monotherapy to improve erectile function in patients with hypogonadism.

Testosterone replacement is the mainstay of therapy for patients with a hypogonadal level of testosterone and symptoms consistent with testosterone deficiency syndrome (TDS), as outlined in other clinical guidelines ${ }^{94}$. Patients initiating testosterone therapy need to be informed of both the potential benefits and risks of treatment, including side effects and serious adverse events. Testosterone therapy improves overall sexual function and sexual quality of life in patients with TDS $^{95}$, however the panel wanted to address the specific question of whether testosterone therapy alone improved erectile function in patients with low testosterone levels.

The panel reviewed six RCTs ${ }^{96-101}$ that randomized hypogonadal patients with erectile dysfunction to treatment with testosterone replacement $(n=457)$ or placebo $(n=459)$ and compared improvement in erectile function between these two arms. The follow-up period in these studies ranged from 3 to 12 months. The baseline testosterone level to be enrolled in the 
studies differed (range $<8$ to $<15 \mathrm{nmol} / \mathrm{L}$ ) and there was some heterogeneity in the testosterone replacement regimens used, with four studies using testosterone gel at $50 \mathrm{mg} / \mathrm{d}^{97}$, $98,100,101$, one study using a testosterone patch at $50 \mathrm{mg} / \mathrm{d}^{96}$ and one study using intramuscular (IM) testosterone undecanoate $1000 \mathrm{mg} / 12$ weeks ${ }^{99}$. Additionally, these studies did not routinely report what the testosterone levels were at the end of the study. Despite the heterogeneity and methodological considerations, these six RCTs were chosen as they had the least risk of bias amongst other RCTs published on this topic. Our meta-analysis demonstrates a mean increase in IIEF-EF score of 2.65 (95\% CI: 0.81, 4.48) with testosterone therapy compared to placebo with a moderate certainty in evidence, indicating testosterone therapy alone unlikely leads to a clinically significant improvement in erectile function in this patient population. These findings are similar to the meta-analysis conducted by Corona and colleagues, which included six studies only including participants with a baseline testosterone level below $8 \mathrm{nmol} / \mathrm{L}^{95}$. In this meta-analysis, the mean increase in IIEF-EF score is 2.95 (95\% CI: 1.86, 4.03), which remains below the MCID.

\section{Dual PDE5i and testosterone therapy}

While current evidence does not support the use of testosterone as monotherapy for the treatment of erectile dysfunction in hypogonadal patients, there is some evidence to supports its use as a combination therapy to salvage patients who have failed PDE5is. Numerous noncontrolled trials have shown promising results, especially in patients with lower testosterone levels. However, the degree of erectile function improvement is not as profound in controlled trials $^{102,103}$. Three RCTs ${ }^{104-106}$ randomized 326 PDE5 inhibitor non-responders with low to low-normal testosterone levels to combination treatment with either testosterone or placebo over a follow-up period ranging from 4 to 16 weeks. The meta-analysis of these three trials demonstrated a mean increase in the IIEF-EF score of 1.68 (95\% CI: 0.30, 3.07) favoring testosterone combination therapy with a low certainty of evidence. Given this uncertainty, sufficiently powered controlled trials with longer follow-up are required in order to definitely address this claim.

\section{Among patients with erectile dysfunction, does increasing physical activity improve erectile function compared to usual activity?}

Based on the available evidence, the panel conditionally recommends for patients to increase their physical activity to improve their erectile function.

The panel reviewed five RCTs ${ }^{107-111}$ comparing improvement of erectile function between patients continuing their regular physical activity level $(n=149)$ or an increased physical activity level $(n=217)$ over a follow-up period ranging from 2 to 24 months. In

addition to ED, participants in the RCTs also had obesity ${ }^{107}$, ischemic heart disease ${ }^{108}$, 
hypertension ${ }^{109}$ and metabolic syndrome ${ }^{111}$. Two studies treated both the intervention and control arms with PDE5-inhibitors as part of the study design ${ }^{110,111}$. The exact prescribed physical activity and exercise routines differed amongst the trials, however the goal in each trial was to increase exercise tolerance through aerobic and/or resistance training. The metaanalysis demonstrates a mean increase in the IIEF-EF score of 3.77 (95\% CI: 2.04, 5.50), favouring an increased physical activity level, with a low certainty of evidence. Although the improvement in IIEF-EF score is borderline for clinical significance, the safety, relatively low cost, wide accessibility and acceptability of physical activity in the general population influenced the panel to conditionally recommend an increase in physical activity in the ED population. There is a linear relationship between physical activity and overall health status and regular physical activity is a proven primary and secondary prevention strategy in numerous medical conditions, many of which are also associated with $\mathrm{ED}^{112}$.

\section{Among patients with post-prostatectomy erectile dysfunction, should penile rehabilitation with scheduled PDE5 inhibitor be used over no intervention?}

Based on the available evidence, the panel conditionally recommends against penile rehabilitation with scheduled PDE5is following RP.

Sexual dysfunction is a significant survivorship concern impacting patients undergoing localized treatment for prostate cancer, with the vast majority of patients having some functional impact after treatment despite advancements in surgical technique. Recovery of erectile function is dependent on both treatment and patient-related factors, and a subset of patients will not experience recovery ${ }^{19,113}$. Penile rehabilitation is the concept of using interventions to promote the natural recovery of erectile function after an insult to the erectile mechanism which occurs after radical prostatectomy (RP), external beam radiation therapy (EBRT), brachytherapy and other localized prostate cancer treatments. Although there is controversy surrounding the utility and ways to perform penile rehabilitation ${ }^{114}$, the majority of studies focus on scheduled PDE5is for variable periods of time leading up to and following RP.

In the post-RP population, the panel reviewed $5 \mathrm{RCTs}^{80,115-118}$ that randomized patients to placebo or no treatment $(n=372)$ or to scheduled PDE5-is $(n=385)$ and compared erectile function restoration rates. The follow-up period in these studies ranged from 24 to 48 weeks. Given methodological issues with these studies leading to a very low certainty of the evidence, the pooled effect estimate suggests that in every 1000 patients who receive penile rehabilitation with scheduled PDE5is, only 28 more patients (95\% CI: 50 fewer, 138 more) experienced ED resolution compared to placebo, which is not statistically significant (RR 1.11 (95\% CI: 0.80, 1.55)). 
Sexual quality of life was assessed using the Expanded Prostate Cancer Index Composite (Sexual Domain) in Montorsi's scheduled tadalafil versus placebo RCT ( $\mathrm{n}=280)$ and the results suggest little to no difference compared to placebo after the cessation of active therapy ${ }^{80}$.

Serious adverse events and treatment discontinuation due to any cause (RR $0.98,95 \%$ CI: 0.72, 1.34) did not significantly differ between scheduled PDE5-inhibitor and placebo in 2 RCTs ( $n=403$ ) that addressed this ${ }^{80,118}$, albeit the certainty of evidence is very low.

\section{Penile rehabilitation post-radiotherapy}

There is insufficient evidence for the panel to make any recommendation for penile rehabilitation following treatment with EBRT and brachytherapy for prostate cancer. Radiation damage affects the erectile mechanism differently than surgical injury, with the pathophysiological factors leading to ED being more cumulative and delayed with radiation ${ }^{119}$. Despite this, proponents of penile rehabilitation believe scheduled PDE5is may limit the damage radiation causes in vascular and cavernous tissues. Scheduled PDE5is after EBRT have been shown to be efficacious in the short term after radiation therapy, with 3 RCTs $^{120-122}$ demonstrating a cumulative increase in IIEF-EF score of 6.10 (95\% CI: 4.69, 7.52) compared to placebo after six weeks of treatment. These studies did not assess longerterm erectile function rates or the protective effect of PDE5is. A small trial of 27 patients compared daily sildenafil treatment taken for six months around the time of prostate brachytherapy $(n=14)$ versus placebo $(n=13)$ and this trial failed to show an improvement in erectile function at one and two years following treatment ${ }^{123}$. A larger RCT by Zelefsky and colleagues ${ }^{124}$ had a similar trial design but included men with EBRT and brachytherapy, and although patients previously receiving the six months of scheduled sildenafil demonstrated higher median erectile function scores at 12 months following therapy (26 versus 21.5, $\mathrm{p}=0.018$ ), the median IIEF-EF of both arms was identical at 25 at the two year mark. Although there is insufficient data to make a recommendation, limited evidence suggests that scheduled PDE5is taken around the time of radiation therapy (EBRT and/or brachytherapy) do not offer any long-term protective effects against future ED.

\section{Future directions requiring further study}

As technology evolves and a further understanding of the pathophysiological processes contributing to ED develops, we can expect that treatment options to improve erectile function will continue to advance. Regenerative therapies aim to restore the structure and function of the erectile tissue and offer a 'cure' to the disease process as opposed to merely a treating the symptom of $\mathrm{ED}^{125}$. Preclinical and early human studies have explored regenerative approaches for treating $\mathrm{ED}$, such as stem cell therapy (SCT), platelet rich plasma 
(PRP) and amniotic fluid matrices. However, these options are currently not approved for use outside of clinical trials and remain experimental ${ }^{125,126 .}$

\section{Stem cell therapy (SCT)}

Stem cells function to release growth factors, cytokines, and chemokines in a paracrine fashion to promote wound healing and rebuild damaged tissues ${ }^{127}$. There have been several small phase I-III human trials evaluating SCT for treating ED, but there is significant variability between protocols, inadequate adverse event reporting, and a lack of long-term follow-up ${ }^{128-131}$.

\section{Platelet-rich plasma (PRP)}

Platelet-rich plasma (PRP) is autologous blood plasma that contains supraphysiologic platelet concentrations ${ }^{132}$ and numerous growth factors implicated in erection recovery ${ }^{133}$. Penile bruising is common after injection and the protocol for injections and growth factor activation is not well studied or universally accepted. Despite the global use of PRP to treat ED, there are a limited number of peer-reviewed human studies to support this experimental regenerative therapy ${ }^{134}$.

\section{Amniotic fluid matrices}

Dehydrated human amnion/chorion membranes have been applied to cavernous nerves during $\mathrm{RP}$ as a source of implantable neurotrophic factors, growth factors, cytokines, proteases, and inhibitors of inflammatory and fibrotic pathways ${ }^{125,135}$. Limited human studies have applied these grafts during robotic-assisted RP with promising clinical outcomes of expedited recovery in erectile function ${ }^{136,137}$. The long-term efficacy, side effects and oncologic consequences of these grafts are unknown at this time and require future study.

\section{Limitations and unanswered questions}

This guideline primarily focused on patients with ED as a single presenting symptom. However, patients presenting with ED often have other concurrent elements of sexual dysfunction (low libido, orgasmic dysfunction, ejaculatory dysfunction), Peyronie's disease, testosterone deficiency, lower urinary tract symptoms/BPH, prostatitis/pelvic pain, psychological or psychiatric conditions, and other medical problems (neurologic, gastrointestinal) that influence both their erectile function directly, and more broadly quality of life as it relates to sexual function. Due to the complexity of the interactions between these factors and the lack of comprehensive studies assessing all of these factors together, the panel was not able to provide recommendations that address the impact that these factors have, individually or collectively, on ED therapy. Therefore, the recommendations in this guideline need to be contextualized based on the patient's history and presenting symptoms and conditions that may be influencing sexual function in its entirety. 
Given the methodology of ED therapeutic trial design, the vast majority of studies referenced in this guideline compare an intervention to placebo and don't assess combination therapy. Synergistic effects of multiple treatments are not specifically addressed in this guideline, however may appropriate depending on the clinical scenario.

It is well known that the MCID in erectile function score depends on initial ED severity, with greater improvements in IIEF-EF score necessary for satisfactory results in patients with more severe $\mathrm{ED}^{35}$. Moreover, the underlying cause of ED may impact treatment response depending on its mechanism of action. Given the methodological challenges in data reporting, including the lack of power and routine reporting of underlying ED etiology, the vast majority of studies do not perform subgroup analyses based on either severity of ED or on the primary cause of ED. ${ }^{17}$ This limitation significantly impacts the panel's ability to make recommendations for specific subgroups of patients with ED based on the current literature.

The panel identified several deficits in the body of literature focussing on ED assessment and treatment, including a lack of quality of life metrics, patient reported outcomes other than erectile function, assessment of partner satisfaction, and a lack of harms data (particularly for some treatments). This made it challenging for the panel to comment on some of the a priori outcomes that were felt to be important when a patient has to make an ED treatment decision. Hopefully future ED studies include these important measures in their design.

\section{Conclusions}

These guidelines were developed using transparent and rigorous methods in order to provide the healthcare community with the most current data and recommendations regarding ED patient assessment and treatment through the Canadian lens. Special attention was taken to provide clarity on the most controversial aspects of ED treatment in Canada today.

Evaluating a patient with ED requires a sufficiently detailed yet focussed history and physical exam to establish an etiologic working diagnosis. Reversible factors contributing to ED should be identified and corrected, including positive lifestyle changes that optimize overall health. In patients requesting treatment, it is reasonable to begin with conservative and less invasive therapies and introduce additional therapeutic measures when necessary, through a shared decision-making process with the patient and their partner. 
Competing interests: Dr. Flannigan has been an advisory board member for Acerus; has received honoraria for speaking and educating from Boston Scientific and Paladin Labs; and participated in a clinical trial on the injection of novel lidocaine polymer for chronic scrotal pain supported by Sustained Therapeutics. Dr. Patel has been an advisory board member for Aytu Biosciences; a consultant for Nestle Health and Boston Scientific; and gave a talk on men's health for Boston Scientific and Paladin. Dr. Krakowsky has been an advisory board member for Acerus, Felix, Paladin, Pfizer, Sprout, and Verity. No other author reports any competing personal or financial interests related to this work.

\section{References}

1. Gratzke C, Angulo J, Chitaley K, et al. Anatomy, physiology, and pathophysiology of erectile dysfunction. J Sex Med. 2010;7(1 Pt 2):445-75. https://doi.org/10.1111/j.17436109.2009.01624.x

2. Canadian Diabetes Association Clinical Practice Guidelines Expert C, Brock G, Harper W. Erectile dysfunction. Can J Diabetes. 2013;37 Suppl 1:S150-2. https://doi.org/10.1016/j.jcjd.2013.01.041

3. Feldman HA, Goldstein I, Hatzichristou DG, et al. Impotence and its medical and psychosocial correlates: results of the Massachusetts Male Aging Study. J Urol. 1994;151(1):54-61. https://doi.org/10.1016/s0022-5347(17)34871-1

4. Rosen RC. Psychogenic erectile dysfunction. Classification and management. Urol Clin North Am. 2001;28(2):269-78. https://doi.org/10.1016/s0094-0143(05)70137-3

5. Vlachopoulos CV, Terentes-Printzios DG, Ioakeimidis NK, et al. Prediction of cardiovascular events and all-cause mortality with erectile dysfunction: a systematic review and meta-analysis of cohort studies. Circ Cardiovasc Qual Outcomes. 2013;6(1):99-109. https://doi.org/10.1161/CIRCOUTCOMES.112.966903

6. Corona G, Petrone L, Mannucci E, et al. Assessment of the relational factor in male patients consulting for sexual dysfunction: the concept of couple sexual dysfunction. $J$ Androl. 2006;27(6):795-801. https://doi.org/10.2164/jandrol.106.000638

7. Salonia A, Castagna G, Sacca A, et al. Is erectile dysfunction a reliable proxy of general male health status? The case for the International Index of Erectile Function-Erectile Function domain. J Sex Med. 2012;9(10):2708-15. https://doi.org/10.1111/j.17436109.2012.02869.x

8. Ewane KA, Lin HC, Wang R. Should patients with erectile dysfunction be evaluated for cardiovascular disease? Asian J Androl. 2012;14(1):138-44.

https://doi.org/10.1038/aja.2011.137

9. Inman BA, Sauver JL, Jacobson DJ, et al. A population-based, longitudinal study of erectile dysfunction and future coronary artery disease. Mayo Clin Proc. 2009;84(2):108-13. https://doi.org/10.4065/84.2.108

10. Araujo AB, Hall SA, Ganz P, et al. Does erectile dysfunction contribute to cardiovascular disease risk prediction beyond the Framingham risk score? J Am Coll Cardiol. 2010;55(4):350-6. https://doi.org/10.1016/j.jacc.2009.08.058 
11. Dong JY, Zhang YH, Qin LQ. Erectile dysfunction and risk of cardiovascular disease: meta-analysis of prospective cohort studies. J Am Coll Cardiol. 2011;58(13):1378-85. https://doi.org/10.1016/j.jacc.2011.06.024

12. Gandaglia G, Briganti A, Jackson G, et al. A systematic review of the association between erectile dysfunction and cardiovascular disease. Eur Urol. 2014;65(5):968-78. https://doi.org/10.1016/j.eururo.2013.08.023

13. Chew KK, Finn J, Stuckey B, et al. Erectile dysfunction as a predictor for subsequent atherosclerotic cardiovascular events: findings from a linked-data study. J Sex Med. 2010;7(1 Pt 1):192-202. https://doi.org/10.1111/j.1743-6109.2009.01576.x

14. Feng $\mathrm{C}, \mathrm{Xu} \mathrm{YM}$, Barbagli $\mathrm{G}$, et al. The relationship between erectile dysfunction and open urethroplasty: a systematic review and meta-analysis. J Sex Med. 2013;10(8):2060-8. https://doi.org/10.1111/jsm.12181

15. Johnsen NV, Kaufman MR, Dmochowski RR, et al. Erectile Dysfunction Following Pelvic Fracture Urethral Injury. Sex Med Rev. 2018;6(1):114-23.

https://doi.org/10.1016/j.sxmr.2017.06.004

16. El-Assmy A, El-Tholoth HS, Abou-El-Ghar ME, et al. Risk factors of erectile dysfunction and penile vascular changes after surgical repair of penile fracture. Int J Impot Res. 2012;24(1):20-5. https://doi.org/10.1038/ijir.2011.41

17. Capogrosso P, Pozzi EP, Celentano V, et al. Erectile Recovery After Radical Pelvic Surgery: Methodological Challenges and Recommendations for Data Reporting. J Sex Med. 2020;17(1):7-16. https://doi.org/10.1016/j.jsxm.2019.09.013

18. Gaither TW, Awad MA, Osterberg EC, et al. The Natural History of Erectile Dysfunction After Prostatic Radiotherapy: A Systematic Review and Meta-Analysis. J Sex Med. 2017;14(9):1071-8. https://doi.org/10.1016/j.jsxm.2017.07.010

19. Resnick MJ, Koyama T, Fan KH, et al. Long-term functional outcomes after treatment for localized prostate cancer. N Engl J Med. 2013;368(5):436-45.

https://doi.org/10.1056/NEJMoa1209978

20. Seftel AD, de la Rosette J, Birt J, et al. Coexisting lower urinary tract symptoms and erectile dysfunction: a systematic review of epidemiological data. Int J Clin Pract. 2013;67(1):32-45. https://doi.org/10.1111/ijcp.12044

21. Li HJ, Kang DY. Prevalence of sexual dysfunction in men with chronic prostatitis/chronic pelvic pain syndrome: a meta-analysis. World J Urol. 2016;34(7):1009-17. https://doi.org/10.1007/s00345-015-1720-3

22. Chevret M, Jaudinot E, Sullivan K, et al. Impact of erectile dysfunction (ED) on sexual life of female partners: assessment with the Index of Sexual Life (ISL) questionnaire. $J$ Sex Marital Ther. 2004;30(3):157-72. https://doi.org/10.1080/00926230490262366

23. Korfage IJ, Pluijm S, Roobol M, et al. Erectile dysfunction and mental health in a general population of older men. J Sex Med. 2009;6(2):505-12. https://doi.org/10.1111/j.17436109.2008.01111.x

24. Colson MH. Couple, ways of couples coping, and erectile dysfunction. Gynecol Obstet Fertil. 2007;35(2):129-34. https://doi.org/10.1016/j.gyobfe.2006.10.034

25. Fisher WA, Eardley I, McCabe M, et al. Erectile dysfunction (ED) is a shared sexual concern of couples II: association of female partner characteristics with male partner ED 
treatment seeking and phosphodiesterase type 5 inhibitor utilization. $J$ Sex Med. 2009;6(11):3111-24. https://doi.org/10.1111/j.1743-6109.2009.01432.x

26. Li H, Gao T, Wang R. The role of the sexual partner in managing erectile dysfunction. Nat Rev Urol. 2016;13(3):168-77. https://doi.org/10.1038/nrurol.2015.315

27. Guyatt GH, Oxman AD, Vist GE, et al. GRADE: an emerging consensus on rating quality of evidence and strength of recommendations. BMJ. 2008;336(7650):924-6. https://doi.org/10.1136/bmj.39489.470347.AD

28. Alonso-Coello P, Schunemann HJ, Moberg J, et al. GRADE Evidence to Decision (EtD) frameworks: a systematic and transparent approach to making well informed healthcare choices. 1: Introduction. BMJ. 2016;353:i2016. https://doi.org/10.1136/bmj.i2016

29. Guyatt GH, Oxman AD, Kunz R, et al. What is "quality of evidence" and why is it important to clinicians? BMJ. 2008;336(7651):995-8. https://doi.org/10.1136/bmj.39490.551019.BE

30. Balshem H, Helfand M, Schunemann HJ, et al. GRADE guidelines: 3. Rating the quality of evidence. J Clin Epidemiol. 2011;64(4):401-6. https://doi.org/10.1016/j.jclinepi.2010.07.015

31. Alonso-Coello P, Oxman AD, Moberg J, et al. GRADE Evidence to Decision (EtD) frameworks: a systematic and transparent approach to making well informed healthcare choices. 2: Clinical practice guidelines. BMJ. 2016;353:i2089. https://doi.org/10.1136/bmj.i2089

32. Guyatt GH, Oxman AD, Santesso N, et al. GRADE guidelines: 12. Preparing summary of findings tables-binary outcomes. J Clin Epidemiol. 2013;66(2):158-72. https://doi.org/10.1016/j.jclinepi.2012.01.012

33. Guyatt GH, Thorlund K, Oxman AD, et al. GRADE guidelines: 13. Preparing summary of findings tables and evidence profiles-continuous outcomes. J Clin Epidemiol. 2013;66(2):173-83. https://doi.org/10.1016/j.jclinepi.2012.08.001

34. Rosen RC, Cappelleri JC, Gendrano N, 3rd. The International Index of Erectile Function (IIEF): a state-of-the-science review. Int J Impot Res. 2002;14(4):226-44. https://doi.org/10.1038/sj.ijir.3900857

35. Rosen RC, Allen KR, Ni X, et al. Minimal clinically important differences in the erectile function domain of the International Index of Erectile Function scale. Eur Urol. 2011;60(5):1010-6. https://doi.org/10.1016/j.eururo.2011.07.053

36. Park BY, Wilson G, Berger J, et al. Is Internet Pornography Causing Sexual Dysfunctions? A Review with Clinical Reports. Behav Sci (Basel). 2016;6(3). https://doi.org/10.3390/bs6030017

37. Grubbs JB, Gola M. Is Pornography Use Related to Erectile Functioning? Results From Cross-Sectional and Latent Growth Curve Analyses. J Sex Med. 2019;16(1):111-25. https://doi.org/10.1016/j.jsxm.2018.11.004

38. Landripet I, Stulhofer A. Is Pornography Use Associated with Sexual Difficulties and Dysfunctions among Younger Heterosexual Men? J Sex Med. 2015;12(5):1136-9. https://doi.org/10.1111/jsm.12853 
39. Montorsi F, Adaikan G, Becher E, et al. Summary of the recommendations on sexual dysfunctions in men. J Sex Med. 2010;7(11):3572-88. https://doi.org/10.1111/j.17436109.2010.02062.x

40. Coyne K, Mandalia S, McCullough S, et al. The International Index of Erectile Function: development of an adapted tool for use in HIV-positive men who have sex with men. J Sex Med. 2010;7(2 Pt 1):769-74. https://doi.org/10.1111/j.1743-6109.2009.01579.x 41. Ghanem HM, Salonia A, Martin-Morales A. SOP: physical examination and laboratory testing for men with erectile dysfunction. J Sex Med. 2013;10(1):108-10. https://doi.org/10.1111/j.1743-6109.2012.02734.x

42. Elhanbly S, Elkholy A. Nocturnal penile erections: the role of RigiScan in the diagnosis of vascular erectile dysfunction. J Sex Med. 2012;9(12):3219-26. https://doi.org/10.1111/j.1743-6109.2012.02954.x

43. Sikka SC, Hellstrom WJ, Brock G, et al. Standardization of vascular assessment of erectile dysfunction: standard operating procedures for duplex ultrasound. J Sex Med. 2013;10(1):120-9. https://doi.org/10.1111/j.1743-6109.2012.02825.x

44. Bella AJ, Lee JC, Carrier S, et al. 2015 CUA Practice guidelines for erectile dysfunction. Can Urol Assoc J. 2015;9(1-2):23-9. https://doi.org/10.5489/cuaj.2699 45. Burnett AL, Nehra A, Breau RH, et al. Erectile Dysfunction: AUA Guideline. J Urol. 2018;200(3):633-41. https://doi.org/10.1016/j.juro.2018.05.004

46. Silva AB, Sousa N, Azevedo LF, et al. Physical activity and exercise for erectile dysfunction: systematic review and meta-analysis. Br J Sports Med. 2017;51(19):1419-24. https://doi.org/10.1136/bjsports-2016-096418

47. Allen MS, Walter EE. Health-Related Lifestyle Factors and Sexual Dysfunction: A Meta-Analysis of Population-Based Research. J Sex Med. 2018;15(4):458-75. https://doi.org/10.1016/j.jsxm.2018.02.008

48. Pizzol D, Demurtas J, Stubbs B, et al. Relationship Between Cannabis Use and Erectile Dysfunction: A Systematic Review and Meta-Analysis. Am J Mens Health. 2019;13(6):1557988319892464. https://doi.org/10.1177/1557988319892464

49. Rhim HC, Kim MS, Park YJ, et al. The Potential Role of Arginine Supplements on Erectile Dysfunction: A Systemic Review and Meta-Analysis. J Sex Med. 2019;16(2):223-34. https://doi.org/10.1016/j.jsxm.2018.12.002

50. El Taieb M, Hegazy E, Ibrahim A. Daily Oral l-Arginine Plus Tadalafil in Diabetic Patients with Erectile Dysfunction: A Double-Blinded, Randomized, Controlled Clinical Trial. J Sex Med. 2019;16(9):1390-7. https://doi.org/10.1016/j.jsxm.2019.06.009 51. El-Wakeel LM, Fouad FA, Saleem MD, et al. Efficacy and tolerability of sildenafil/1arginine combination relative to sildenafil alone in patients with organic erectile dysfunction. Andrology. 2020;8(1):143-7. https://doi.org/10.1111/andr.12671

52. Andersson E, Walén C, Hallberg J, et al. A randomized controlled trial of guided Internet-delivered cognitive behavioral therapy for erectile dysfunction. J Sex Med. 2011;8(10):2800-9. https://doi.org/10.1111/j.1743-6109.2011.02391.x 53. Titta M, Tavolini IM, Dal Moro F, et al. Sexual counseling improved erectile rehabilitation after non-nerve-sparing radical retropubic prostatectomy or cystectomy--results 
of a randomized prospective study. J Sex Med. 2006;3(2):267-73. https://doi.org/10.1111/j.1743-6109.2006.00219.x

54. Banner LL, Anderson RU. Integrated sildenafil and cognitive-behavior sex therapy for psychogenic erectile dysfunction: a pilot study. J Sex Med. 2007;4(4 Pt 2):1117-25. https://doi.org/10.1111/j.1743-6109.2007.00535.x

55. Qiu X, Lin G, Xin Z, et al. Effects of low-energy shockwave therapy on the erectile function and tissue of a diabetic rat model. J Sex Med. 2013;10(3):738-46. https://doi.org/10.1111/jsm.12024

56. Campbell JD, Burnett AL. Neuroprotective and Nerve Regenerative Approaches for Treatment of Erectile Dysfunction after Cavernous Nerve Injury. Int J Mol Sci. 2017;18(8). https://doi.org/10.3390/ijms18081794

57. Goldenberg MM. Safety and efficacy of sildenafil citrate in the treatment of male erectile dysfunction. Clin Ther. 1998;20(6):1033-48. https://doi.org/10.1016/s01492918(98)80103-3

58. Huang SA, Lie JD. Phosphodiesterase-5 (PDE5) Inhibitors In the Management of Erectile Dysfunction. P T. 2013;38(7):407-19.

59. Doggrell S. Do vardenafil and tadalafil have advantages over sildenafil in the treatment of erectile dysfunction? Int J Impot Res. 2007;19(3):281-95. https://doi.org/10.1038/sj.ijir.3901525

60. Park NC, Kim TN, Park HJ. Treatment Strategy for Non-Responders to PDE5 Inhibitors. World J Mens Health. 2013;31(1):31-5. https://doi.org/10.5534/wjmh.2013.31.1.31 61. Yuan J, Zhang R, Yang Z, et al. Comparative effectiveness and safety of oral phosphodiesterase type 5 inhibitors for erectile dysfunction: a systematic review and network meta-analysis. Eur Urol. 2013;63(5):902-12. https://doi.org/10.1016/j.eururo.2013.01.012 62. Fulgham PF, Cochran JS, Denman JL, et al. Disappointing initial results with transurethral alprostadil for erectile dysfunction in a urology practice setting. J Urol. 1998;160(6 Pt 1):2041-6. https://doi.org/10.1097/00005392-199812010-00028

63. Guay AT, Perez JB, Velasquez E, et al. Clinical experience with intraurethral alprostadil (MUSE) in the treatment of men with erectile dysfunction. A retrospective study. Medicated urethral system for erection. Eur Urol. 2000;38(6):671-6. https://doi.org/10.1159/000020360

64. Urciuoli R, Cantisani TA, Carlini M, et al. Prostaglandin E1 for treatment of erectile dysfunction. Cochrane Database Syst Rev. 2004(2):CD001784.

https://doi.org/10.1002/14651858.CD001784.pub2

65. Bosshardt RJ, Farwerk R, Sikora R, et al. Objective measurement of the effectiveness, therapeutic success and dynamic mechanisms of the vacuum device. Br J Urol. 1995;75(6):786-91. https://doi.org/10.1111/j.1464-410x.1995.tb07392.x

66. Witherington R. Vacuum constriction device for management of erectile impotence. $J$ Urol. 1989;141(2):320-2. https://doi.org/10.1016/s0022-5347(17)40752-x

67. Linet OI, Ogrinc FG. Efficacy and safety of intracavernosal alprostadil in men with erectile dysfunction. The Alprostadil Study Group. N Engl J Med. 1996;334(14):873-7. https://doi.org/10.1056/NEJM199604043341401 
68. Govier FE, McClure RD, Weissman RM, et al. Experience with triple-drug therapy in a pharmacological erection program. J Urol. 1993;150(6):1822-4.

https://doi.org/10.1016/s0022-5347(17)35905-0

69. Domes T, Chung E, DeYoung L, et al. Clinical outcomes of intracavernosal injection in postprostatectomy patients: a single-center experience. Urology. 2012;79(1):150-5. https://doi.org/10.1016/j.urology.2011.09.009

70. Lledo-Garcia E, Jara-Rascon J, Moncada Iribarren I, et al. Penile Prosthesis First and Replacement Surgeries: Analysis of Patient and Partner Satisfaction. J Sex Med. 2015;12(7):1646-53. https://doi.org/10.1111/jsm.12932

71. Bennett N, Henry G, Karpman E, et al. Inflatable penile prosthesis implant length with baseline characteristic correlations: preliminary analysis of the PROPPER study. Transl Androl Urol. 2017;6(6):1167-74. https://doi.org/10.21037/tau.2017.12.01

72. Chierigo F, Capogrosso P, Deho F, et al. Long-Term Follow-Up After Penile Prosthesis Implantation-Survival and Quality of Life Outcomes. J Sex Med. 2019;16(11):1827-33. https://doi.org/10.1016/j.jsxm.2019.08.001

73. McMahon C. Comparison of efficacy, safety, and tolerability of on-demand tadalafil and daily dosed tadalafil for the treatment of erectile dysfunction. $J$ Sex Med. 2005;2(3):41525; discussion 25-7. https://doi.org/10.1111/j.1743-6109.2005.20360.x

74. Ciammella P, Badellino S, Botticella A, et al. 7012 Evaluation of the efficacy and safety of Tadalafil $20 \mathrm{mg}$ on demand vs Tadalafil $5 \mathrm{mg}$ once-a-day in the treatment of erectile dysfunction following curative radiotherapy for prostatic carcinoma: preliminary results of a randomized phase II trial. European Journal of Cancer Supplements. 2009;7(2):410. https://doi.org/https://doi.org/10.1016/S1359-6349(09)71390-4

75. Ricardi U, Gontero P, Ciammella P, et al. Efficacy and safety of tadalafil $20 \mathrm{mg}$ on demand vs. tadalafil $5 \mathrm{mg}$ once-a-day in the treatment of post-radiotherapy erectile dysfunction in prostate cancer men: a randomized phase II trial. J Sex Med. 2010;7(8):2851-9. https://doi.org/10.1111/j.1743-6109.2010.01890.x

76. Rubio-Aurioles E, Porst H, Kim ED, et al. A randomized open-label trial with a crossover comparison of sexual self-confidence and other treatment outcomes following tadalafil once a day vs. tadalafil or sildenafil on-demand in men with erectile dysfunction. $J$ Sex Med. 2012;9(5):1418-29. https://doi.org/10.1111/j.1743-6109.2012.02667.x

77. Jamshidian H, Borhan A, Kooraki S, et al. Evaluation of the efficacy of once-daily use of tadalafil vs. on-demand use. Is there a cumulative effect? J Pak Med Assoc.

2012;62(11):1195-8.

78. Kang DH, Lee JY, Chung JH, et al. Comparison of efficacy for erectile function and lower urinary tract symptoms of tadalafil $20 \mathrm{mg}$ on-demand and $5 \mathrm{mg}$ once daily in patients with erectile dysfunction. Int J Clin Pract. 2012;66(8):813-20. https://doi.org/10.1111/j.17421241.2012.02946.x

79. Hatzimouratidis K, Buvat J, Buttner H, et al. Psychosocial outcomes after initial treatment of erectile dysfunction with tadalafil once daily, tadalafil on demand or sildenafil citrate on demand: results from a randomized, open-label study. Int J Impot Res. 2014;26(6):223-9. https://doi.org/10.1038/ijir.2014.15 
80. Montorsi F, Brock G, Stolzenburg JU, et al. Effects of tadalafil treatment on erectile function recovery following bilateral nerve-sparing radical prostatectomy: a randomised placebo-controlled study (REACTT). Eur Urol. 2014;65(3):587-96. https://doi.org/10.1016/j.eururo.2013.09.051

81. Brock G, Ni X, Oelke M, et al. Efficacy of Continuous Dosing of Tadalafil Once Daily vs Tadalafil On Demand in Clinical Subgroups of Men With Erectile Dysfunction: A Descriptive Comparison Using the Integrated Tadalafil Databases. J Sex Med. 2016;13(5):860-75. https://doi.org/10.1016/j.jsxm.2016.02.171

82. Peng Z, Yang L, Dong Q, et al. Efficacy and Safety of Tadalafil Once-a-Day versus Tadalafil On-Demand in Patients with Erectile Dysfunction: A Systematic Review and MetaAnalyses. Urol Int. 2017;99(3):343-52. https://doi.org/10.1159/000477496

83. Conaglen HM, Conaglen JV. Investigating women's preference for sildenafil or tadalafil use by their partners with erectile dysfunction: the partners' preference study. $J$ Sex Med. 2008;5(5):1198-207. https://doi.org/10.1111/j.1743-6109.2008.00774.x

84. Vardi Y, Appel B, Kilchevsky A, et al. Does low intensity extracorporeal shock wave therapy have a physiological effect on erectile function? Short-term results of a randomized, double-blind, sham controlled study. J Urol. 2012;187(5):1769-75. https://doi.org/10.1016/j.juro.2011.12.117

85. Yee $\mathrm{CH}$, Chan ES, Hou SS, et al. Extracorporeal shockwave therapy in the treatment of erectile dysfunction: a prospective, randomized, double-blinded, placebo controlled study. Int J Urol. 2014;21(10):1041-5. https://doi.org/10.1111/iju.12506

86. Srini VS, Reddy RK, Shultz T, et al. Low intensity extracorporeal shockwave therapy for erectile dysfunction: a study in an Indian population. Can J Urol. 2015;22(1):7614-22.

87. Kitrey ND, Gruenwald I, Appel B, et al. Penile Low Intensity Shock Wave Treatment is Able to Shift PDE5i Nonresponders to Responders: A Double-Blind, Sham Controlled Study. J Urol. 2016;195(5):1550-5. https://doi.org/10.1016/j.juro.2015.12.049

88. Fojecki GL, Tiessen S, Osther PJ. Effect of Low-Energy Linear Shockwave Therapy on Erectile Dysfunction-A Double-Blinded, Sham-Controlled, Randomized Clinical Trial. J Sex Med. 2017;14(1):106-12. https://doi.org/10.1016/j.jsxm.2016.11.307

89. Kalyvianakis D, Hatzichristou D. Low-Intensity Shockwave Therapy Improves Hemodynamic Parameters in Patients With Vasculogenic Erectile Dysfunction: A Triplex Ultrasonography-Based Sham-Controlled Trial. J Sex Med. 2017;14(7):891-7. https://doi.org/10.1016/j.jsxm.2017.05.012

90. Kim KS, Jeong HC, Choi SW, et al. Electromagnetic Low-Intensity Extracorporeal Shock Wave Therapy in Patients with Erectile Dysfunction: A Sham-Controlled, DoubleBlind, Randomized Prospective Study. World J Mens Health. 2020;38(2):236-42. https://doi.org/10.5534/wjmh.190130

91. Abraham L, Symonds T, Morris MF. Psychometric validation of a sexual quality of life questionnaire for use in men with premature ejaculation or erectile dysfunction. $J$ Sex Med. 2008;5(3):595-601. https://doi.org/10.1111/j.1743-6109.2007.00749.x

92. Gruenwald I, Appel B, Kitrey ND, et al. Shockwave treatment of erectile dysfunction. Ther Adv Urol. 2013;5(2):95-9. https://doi.org/10.1177/1756287212470696 
93. Schoofs E, Fode M, Capogrosso P, et al. Current guideline recommendations and analysis of evidence quality on low-intensity shockwave therapy for erectile dysfunction. Int $J$ Impot Res. 2019;31(3):209-17. https://doi.org/10.1038/s41443-019-0132-0

94. Grober ED, Krakowsky Y, Khera M, et al. Canadian Urological Association guideline on testosterone deficiency in men: Evidence-based Q\&A. Can Urol Assoc J. 2021;15(5):E234-E43. https://doi.org/10.5489/cuaj.7252

95. Corona G, Rastrelli G, Morgentaler A, et al. Meta-analysis of Results of Testosterone Therapy on Sexual Function Based on International Index of Erectile Function Scores. Eur Urol. 2017;72(6):1000-11. https://doi.org/10.1016/j.eururo.2017.03.032

96. Allan CA, Forbes EA, Strauss BJ, et al. Testosterone therapy increases sexual desire in ageing men with low-normal testosterone levels and symptoms of androgen deficiency. Int J Impot Res. 2008;20(4):396-401. https://doi.org/10.1038/ijir.2008.22

97. Chiang HS, Hwang TI, Hsui YS, et al. Transdermal testosterone gel increases serum testosterone levels in hypogonadal men in Taiwan with improvements in sexual function. Int $J$ Impot Res. 2007;19(4):411-7. https://doi.org/10.1038/sj.ijir.3901562

98. Chiang HS, Cho SL, Lin YC, et al. Testosterone gel monotherapy improves sexual function of hypogonadal men mainly through restoring erection: evaluation by IIEF score. Urology. 2009;73(4):762-6. https://doi.org/10.1016/j.urology.2008.10.019

99. Hackett G, Cole N, Bhartia M, et al. Testosterone replacement therapy with longacting testosterone undecanoate improves sexual function and quality-of-life parameters vs. placebo in a population of men with type 2 diabetes. J Sex Med. 2013;10(6):1612-27. https://doi.org/10.1111/jsm.12146

100. Jones TH, Arver S, Behre HM, et al. Testosterone replacement in hypogonadal men with type 2 diabetes and/or metabolic syndrome (the TIMES2 study). Diabetes Care. 2011;34(4):828-37. https://doi.org/10.2337/dc10-1233

101. Snyder PJ, Bhasin S, Cunningham GR, et al. Effects of Testosterone Treatment in Older Men. N Engl J Med. 2016;374(7):611-24. https://doi.org/10.1056/NEJMoa1506119 102. Aversa A, Francomano D, Lenzi A. Does testosterone supplementation increase PDE5-inhibitor responses in difficult-to-treat erectile dysfunction patients? Expert Opin Pharmacother. 2015;16(5):625-8. https://doi.org/10.1517/14656566.2015.1011124

103. Alhathal N, Elshal AM, Carrier S. Synergetic effect of testosterone and phophodiesterase-5 inhibitors in hypogonadal men with erectile dysfunction: A systematic review. Can Urol Assoc J. 2012;6(4):269-74. https://doi.org/10.5489/cuaj.11291

104. Buvat J, Montorsi F, Maggi M, et al. Hypogonadal men nonresponders to the PDE5 inhibitor tadalafil benefit from normalization of testosterone levels with a $1 \%$ hydroalcoholic testosterone gel in the treatment of erectile dysfunction (TADTEST study). J Sex Med. 2011;8(1):284-93. https://doi.org/10.1111/j.1743-6109.2010.01956.x

105. Shabsigh R, Kaufman JM, Steidle C, et al. Randomized study of testosterone gel as adjunctive therapy to sildenafil in hypogonadal men with erectile dysfunction who do not respond to sildenafil alone. J Urol. 2004;172(2):658-63.

https://doi.org/10.1097/01.ju.0000132389.97804.d7

106. Spitzer M, Basaria S, Travison TG, et al. Effect of testosterone replacement on response to sildenafil citrate in men with erectile dysfunction: a parallel, randomized trial. 
Ann Intern Med. 2012;157(10):681-91. https://doi.org/10.7326/0003-4819-157-10201211200-00004

107. Esposito K, Giugliano F, Di Palo C, et al. Effect of lifestyle changes on erectile dysfunction in obese men: a randomized controlled trial. JAMA. 2004;291(24):2978-84. https://doi.org/10.1001/jama.291.24.2978

108. Kalka D, Domagala Z, Dworak J, et al. Association between physical exercise and quality of erection in men with ischaemic heart disease and erectile dysfunction subjected to physical training. Kardiol Pol. 2013;71(6):573-80. https://doi.org/10.5603/KP.2013.0120 109. Lamina S, Okoye CG, Dagogo TT. Managing erectile dysfunction in hypertension: the effects of a continuous training programme on biomarker of inflammation. BJU Int. 2009;103(9):1218-21. https://doi.org/10.1111/j.1464-410X.2008.08254.x

110. Maio G, Saraeb S, Marchiori A. Physical activity and PDE5 inhibitors in the treatment of erectile dysfunction: results of a randomized controlled study. J Sex Med. 2010;7(6):22018. https://doi.org/10.1111/j.1743-6109.2010.01783.x

111. Maresca L, D'Agostino M, Castaldo L, et al. Exercise training improves erectile dysfunction (ED) in patients with metabolic syndrome on phosphodiesterase-5 (PDE-5) inhibitors. Monaldi Arch Chest Dis. 2013;80(4):177-83. https://doi.org/10.4081/monaldi.2013.5234

112. Warburton DER, Nicol CW, Bredin SSD. Health benefits of physical activity: the evidence. CMAJ. 2006;174(6):801-9. https://doi.org/10.1503/cmaj.051351

113. Robinson JW, Moritz S, Fung T. Meta-analysis of rates of erectile function after treatment of localized prostate carcinoma. Int J Radiat Oncol Biol Phys. 2002;54(4):1063-8. https://doi.org/10.1016/s0360-3016(02)03030-4

114. Clavell-Hernandez J, Wang R. The controversy surrounding penile rehabilitation after radical prostatectomy. Transl Androl Urol. 2017;6(1):2-11.

https://doi.org/10.21037/tau.2016.08.14

115. Aydogdu O, Gokce MI, Burgu B, et al. Tadalafil rehabilitation therapy preserves penile size after bilateral nerve sparing radical retropubic prostatectomy. Int Braz J Urol. 2011;37(3):336-44; discussion 44-6. https://doi.org/10.1590/s1677-55382011000300007 116. Montorsi F, Brock G, Lee J, et al. Effect of nightly versus on-demand vardenafil on recovery of erectile function in men following bilateral nerve-sparing radical prostatectomy. Eur Urol. 2008;54(4):924-31. https://doi.org/10.1016/j.eururo.2008.06.083

117. Pace G, Del Rosso A, Vicentini C. Penile rehabilitation therapy following radical prostatectomy. Disabil Rehabil. 2010;32(14):1204-8.

https://doi.org/10.3109/09638280903511594

118. Padma-Nathan H, McCullough AR, Levine LA, et al. Randomized, double-blind, placebo-controlled study of postoperative nightly sildenafil citrate for the prevention of erectile dysfunction after bilateral nerve-sparing radical prostatectomy. Int J Impot Res. 2008;20(5):479-86. https://doi.org/10.1038/ijir.2008.33

119. van der Wielen GJ, Mulhall JP, Incrocci L. Erectile dysfunction after radiotherapy for prostate cancer and radiation dose to the penile structures: a critical review. Radiother Oncol. 2007;84(2):107-13. https://doi.org/10.1016/j.radonc.2007.07.018 
120. Watkins Bruner D, James JL, Bryan CJ, et al. Randomized, Double-Blinded, PlaceboControlled Crossover Trial of Treating Erectile Dysfunction with Sildenafil After Radiotherapy and Short-Term Androgen Deprivation Therapy: Results of RTOG 0215. The Journal of Sexual Medicine. 2011;8(4):1228-38. https://doi.org/https://doi.org/10.1111/j.1743-6109.2010.02164.x 121. Incrocci L, Koper PC, Hop WC, et al. Sildenafil citrate (Viagra) and erectile dysfunction following external beam radiotherapy for prostate cancer: a randomized, doubleblind, placebo-controlled, cross-over study. Int J Radiat Oncol Biol Phys. 2001;51(5):1190-5. https://doi.org/10.1016/s0360-3016(01)01767-9

122. Incrocci L, Slagter C, Slob AK, et al. A randomized, double-blind, placebo-controlled, cross-over study to assess the efficacy of tadalafil (Cialis) in the treatment of erectile dysfunction following three-dimensional conformal external-beam radiotherapy for prostatic carcinoma. Int J Radiat Oncol Biol Phys. 2006;66(2):439-44. https://doi.org/10.1016/j.ijrobp.2006.04.047

123. Ilic D, Hindson B, Duchesne G, et al. A randomised, double-blind, placebo-controlled trial of nightly sildenafil citrate to preserve erectile function after radiation treatment for prostate cancer. J Med Imaging Radiat Oncol. 2013;57(1):81-8. https://doi.org/10.1111/j.1754-9485.2012.02461.x

124. Zelefsky MJ, Shasha D, Branco RD, et al. Prophylactic sildenafil citrate improves select aspects of sexual function in men treated with radiotherapy for prostate cancer. $J$ Urol. 2014;192(3):868-74. https://doi.org/10.1016/j.juro.2014.02.097

125. Campbell JD, Milenkovic U, Usta MF, et al. The good, bad, and the ugly of regenerative therapies for erectile dysfunction. Transl Androl Urol. 2020;9(Suppl 2):S252S61. https://doi.org/10.21037/tau.2019.10.06

126. SMSNA Position Statement on Restorative Therapies for ED [press release]. March 27, 2018. Available from: https://www.issm.info/news/public-policy/smsna-releases-positionstatement-on-restorative-therapies-for-erectile-dys/

127. Matz EL, Terlecki R, Zhang Y, et al. Stem Cell Therapy for Erectile Dysfunction. Sex Med Rev. 2019;7(2):321-8. https://doi.org/10.1016/j.sxmr.2017.12.008

128. Al Demour S, Jafar H, Adwan S, et al. Safety and Potential Therapeutic Effect of Two Intracavernous Autologous Bone Marrow Derived Mesenchymal Stem Cells injections in Diabetic Patients with Erectile Dysfunction: An Open Label Phase I Clinical Trial. Urol Int. 2018;101(3):358-65. https://doi.org/10.1159/000492120

129. Yiou R. Stem-cell therapy for erectile dysfunction. Biomed Mater Eng. 2017;28(s1):S81-S5. https://doi.org/10.3233/BME-171627

130. He M, von Schwarz ER. Stem-cell therapy for erectile dysfunction: a review of clinical outcomes. Int J Impot Res. 2021;33(3):271-7. https://doi.org/10.1038/s41443-0200279-8

131. Lokeshwar SD, Patel P, Shah SM, et al. A Systematic Review of Human Trials Using Stem Cell Therapy for Erectile Dysfunction. Sex Med Rev. 2020;8(1):122-30.

https://doi.org/10.1016/j.sxmr.2019.08.003 
132. Sampson S, Gerhardt M, Mandelbaum B. Platelet rich plasma injection grafts for musculoskeletal injuries: a review. Curr Rev Musculoskelet Med. 2008;1(3-4):165-74. https://doi.org/10.1007/s12178-008-9032-5

133. Epifanova MV, Gvasalia BR, Durashov MA, et al. Platelet-Rich Plasma Therapy for Male Sexual Dysfunction: Myth or Reality? Sex Med Rev. 2020;8(1):106-13. https://doi.org/10.1016/j.sxmr.2019.02.002

134. Scott S, Roberts M, Chung E. Platelet-Rich Plasma and Treatment of Erectile Dysfunction: Critical Review of Literature and Global Trends in Platelet-Rich Plasma Clinics. Sex Med Rev. 2019;7(2):306-12. https://doi.org/10.1016/j.sxmr.2018.12.006

135. Lei J, Priddy LB, Lim JJ, et al. Identification of Extracellular Matrix Components and Biological Factors in Micronized Dehydrated Human Amnion/Chorion Membrane. Adv Wound Care (New Rochelle). 2017;6(2):43-53. https://doi.org/10.1089/wound.2016.0699 136. Razdan S, Bajpai RR, Sanchez MA. A matched and controlled longitudinal cohort study of dehydrated human amniotic membrane allograft sheet used as a wraparound nerve bundles in robotic-assisted laparoscopic radical prostatectomy: a puissant adjunct for enhanced potency outcomes. J Robot Surg. 2019;13(3):475-81.

https://doi.org/10.1007/s11701-018-0873-7

137. Patel VR, Samavedi S, Bates AS, et al. Dehydrated Human Amnion/Chorion Membrane Allograft Nerve Wrap Around the Prostatic Neurovascular Bundle Accelerates Early Return to Continence and Potency Following Robot-assisted Radical Prostatectomy: Propensity Score-matched Analysis. Eur Urol. 2015;67(6):977-80.

https://doi.org/10.1016/j.eururo.2015.01.012

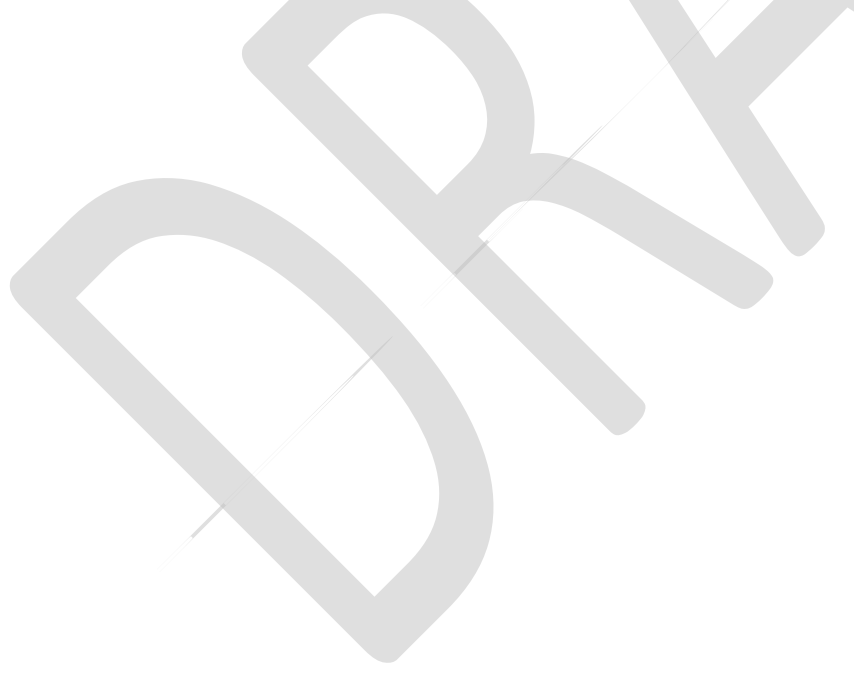




\section{Figures and Tables}

Fig 1. Management summary of erectile dysfunction.

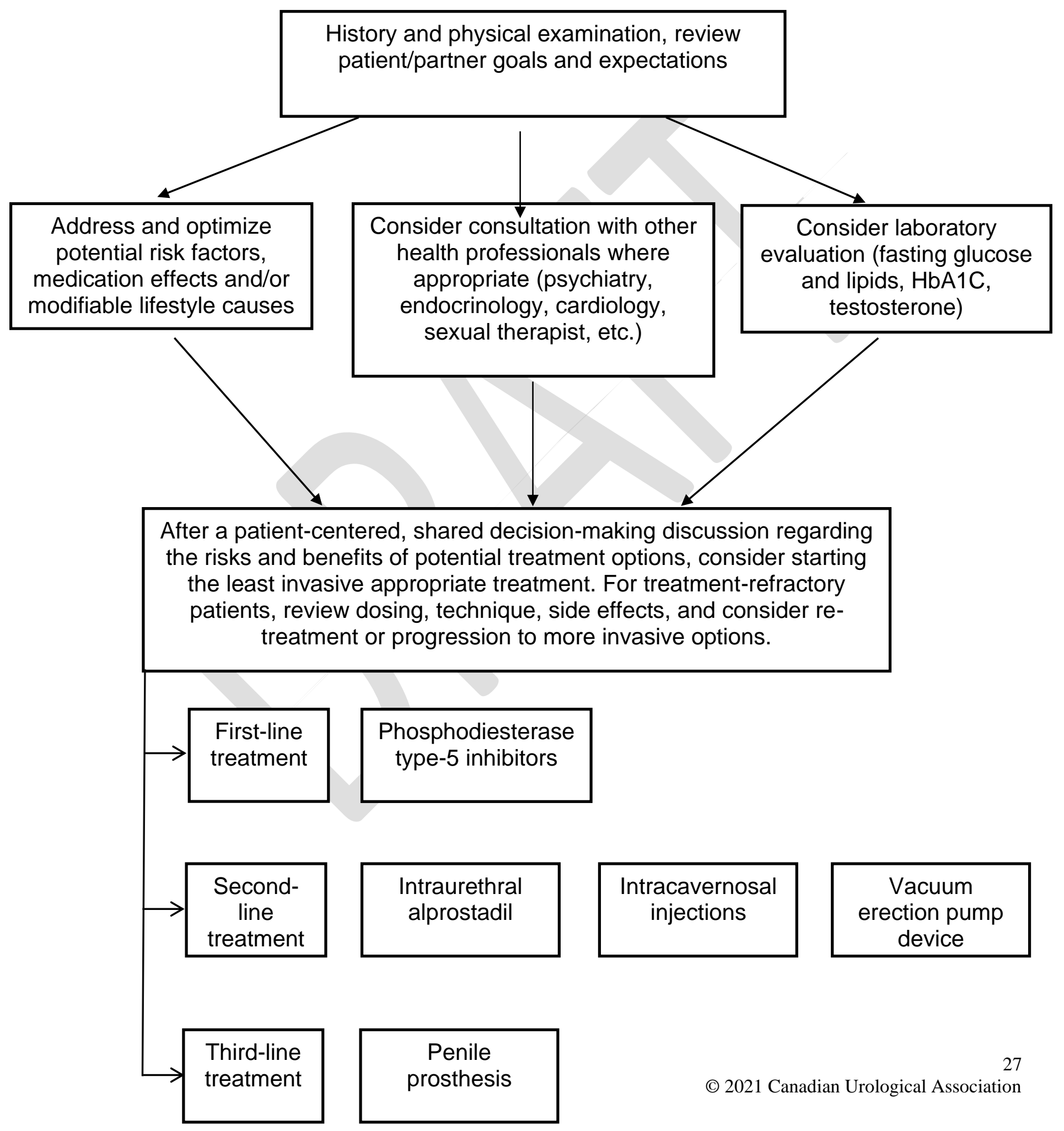




\begin{tabular}{|l|c|c|}
\hline $\begin{array}{l}\text { Table 1. Questions that may help to differentiate psychogenic from } \\
\text { organic erectile dysfunction }\end{array}$ & Psychogenic ED & Organic ED \\
\hline Question & Often present & Reduced \\
\hline $\begin{array}{l}\text { Presence of nocturnal } \\
\text { erections? }\end{array}$ & Often present & Reduced \\
\hline $\begin{array}{l}\text { Presence of erection } \\
\text { during masturbation or } \\
\text { with alternate partners? }\end{array}$ & Strong impact & Minimal impact \\
\hline $\begin{array}{l}\text { Significant recent } \\
\text { psychosocial stress? }\end{array}$ & Strong impact & Minimal impact \\
\hline $\begin{array}{l}\text { Feelings of performanc } \\
\text { anxiety around sexual } \\
\text { activity? }\end{array}$ & & \\
\hline $\begin{array}{l}\text { Situational variability } \\
\text { erectile dysfunction } \\
\text { (improved while on } \\
\text { vacation)? }\end{array}$ & Potential for wide & Minimal variability \\
\hline
\end{tabular}

\begin{tabular}{|l|l|}
\hline \multicolumn{2}{|l|}{ Table 2. Erectile dysfunction validated assessment tools } \\
\hline Tool & Summary \\
\hline $\begin{array}{l}\text { Erection Hardness Scale } \\
\text { (EHS) }\end{array}$ & $\begin{array}{l}\text { Self-reported assessment of penile hardness on a } \\
\text { scale of 0 (no engorgement) to 4 (complete rigidity) }\end{array}$ \\
\hline $\begin{array}{l}\text { Sexual Health Inventory of } \\
\text { Men (SHIM) }\end{array}$ & $\begin{array}{l}\text { Five questions that provide a score out of 25 for the } \\
\text { subjective patient-reported assessment of erectile } \\
\text { dysfunction }\end{array}$ \\
\hline $\begin{array}{l}\text { International Inventory of } \\
\text { Erectile Function (IIEF) }\end{array}$ & $\begin{array}{l}\text { Fifteen questions exploring five domains (desire, } \\
\text { erectile function, intercourse satisfaction, orgasmic } \\
\text { function and overall sexual satisfaction) of sexual } \\
\text { function }\end{array}$ \\
\hline
\end{tabular}




\begin{tabular}{|l|l|}
\hline Table 3. Physical exam for erectile dysfunction \\
\hline Area & Factors to be assessed \\
\hline Overall & $\begin{array}{l}\text { Blood pressure, body habitus, virilization, } \\
\text { mood, gynecomastia }\end{array}$ \\
\hline Penis and Groins & $\begin{array}{l}\text { Penile length and girth, presence of penile } \\
\text { plaques, phimosis, frenular tether, meatal } \\
\text { stenosis, quality of femoral pulses }\end{array}$ \\
\hline Testicles & Volume and consistency \\
\hline
\end{tabular}

Table 4. Comparison of the properties of PDE5-inhibitors

\begin{tabular}{|c|c|c|c|}
\hline Property & Sildenafil & Tadalafil & Vardenafil \\
\hline$>\mathrm{T}_{\mathrm{MAX}}$ & $\begin{array}{c}\text { 30-120 minutes } \\
\text { (median } 60 \text { minutes) }\end{array}$ & $\begin{array}{c}\text { 30-360 minutes } \\
\text { (median } 120 \text { minutes) }\end{array}$ & $\begin{array}{c}\text { 30-120 minutes } \\
\text { (median } 60 \text { minutes) }\end{array}$ \\
\hline $\mathrm{T}_{1 / 2}$ & 4 hours & 17.5 hours & 4 hours \\
\hline Absorption & $\begin{array}{c}\text { Fatty meals cause a } \\
\text { mean delay in TMAX } \\
\text { of } 60 \text { minutes }\end{array}$ & Not affected by food & $\begin{array}{l}\text { Fatty meals cause a } \\
\text { reduction in CMAX }\end{array}$ \\
\hline Available doses & $25 \mathrm{mg}, 50 \mathrm{mg}$, & $\begin{array}{l}2.5 \mathrm{mg}, 5 \mathrm{mg} \text { daily } \\
5 \mathrm{mg}, 10 \mathrm{mg}, 20 \mathrm{mg} \\
\text { PRN }\end{array}$ & $\begin{array}{c}10 \mathrm{mg} \text { oral } \\
\text { dissolvable tablet } \\
2.5 \mathrm{mg}, 5 \mathrm{mg}, 10 \mathrm{mg}, \\
20 \mathrm{mg} \text { PRN }\end{array}$ \\
\hline Maximum dose & 100 mg daily & $20 \mathrm{mg}$ daily & $20 \mathrm{mg}$ daily \\
\hline Efficacy & \multicolumn{3}{|c|}{ Each of the PDE5 inhibitors offers similar efficacy } \\
\hline $\begin{array}{l}\text { Dose adjustments } \\
\text { may be needed for }\end{array}$ & $\begin{aligned}- & \text { Patients }>65 \text { years } \\
- & \text { Hepatic } \\
& \text { impairment } \\
- & \text { Renal impairment } \\
& (\mathrm{CrCl}<30\end{aligned}$ & $\begin{aligned}- & \text { Patients >65 years } \\
- & \text { Hepatic } \\
& \text { impairment } \\
- & \text { Renal impairment } \\
& (\mathrm{CrCl}<30\end{aligned}$ & $\begin{aligned}- & \text { Patients }>65 \text { years } \\
- & \text { Hepatic } \\
& \text { impairment } \\
- & \text { Renal impairment } \\
& (\mathrm{CrCl}<30 \mathrm{ml} / \mathrm{min})\end{aligned}$ \\
\hline
\end{tabular}




\begin{tabular}{|c|c|c|c|}
\hline & $\begin{array}{l}\mathrm{ml} / \mathrm{min}) \\
- \text { Concomitant use } \\
\text { of potent } \\
\text { cytochrome P450 } \\
\text { 3A4 inhibitors, } \\
\text { such as ritonavir } \\
\text { and erythromycin } \\
- \text { Concomitant use } \\
\text { of cimetidine }\end{array}$ & $\begin{array}{l}\mathrm{ml} / \mathrm{min}) \\
- \text { Concomitant use } \\
\text { of potent } \\
\text { cytochrome } \mathrm{P} 450 \\
\text { 3A4 inhibitors, } \\
\text { such as ritonavir } \\
\text { and erythromycin }\end{array}$ & $\begin{array}{l}\text { - Concomitant use } \\
\text { of potent } \\
\text { cytochrome P450 } \\
\text { 3A4 inhibitors, } \\
\text { such as ritonavir } \\
\text { and erythromycin }\end{array}$ \\
\hline Contraindications & \multicolumn{3}{|c|}{$\begin{array}{l}\text { Any patient using organic nitrates either regularly or intermittently } \\
\text { Known hypersensitivity to any component of the tablet }\end{array}$} \\
\hline $\begin{array}{l}\text { Side effects (five } \\
\text { most common in } \\
\text { order of } \\
\text { frequency when } \\
\text { compared to } \\
\text { placebo) }\end{array}$ & $\begin{array}{l}\text { Headache, flushing, } \\
\text { dyspepsia, nasal } \\
\text { congestion, alteration } \\
\text { in color vision }\end{array}$ & $\begin{array}{c}\text { Headache, dyspepsia, } \\
\text { back pain, myalgia, } \\
\text { nasal congestion }\end{array}$ & $\begin{array}{l}\text { Headache, flushing, } \\
\text { rhinitis, dyspepsia, } \\
\text { sinusitis }\end{array}$ \\
\hline
\end{tabular}

Please consult the individual product monographs for additional information. Adapted from references 44 and 58 .

Table 5. CUA erectile dysfunction guideline: Summary of recommendations

1. Among patients with erectile dysfunction, should daily tadalafil be preferentially prescribed instead of on-demand tadalafil?

We suggest against the preferential use of daily tadalafil rather than on-

Conditional demand tadalafil for patients with erectile dysfunction recommendation, low levels of certainty in evidence

2. Among patients with erectile dysfunction, should low-intensity shockwave therapy (Li-SWT) b recommended over no treatment?

We suggest against the use of low-intensity shockwave therapy for patients with erectile dysfunction

Conditional recommendation, low levels of certainty in evidence

\section{Among patients with erectile dysfunction and hypogonadism, should testosterone}




\begin{tabular}{|l|c|}
\hline replacement be used as monotherapy compared to no treatment? \\
\hline $\begin{array}{l}\text { We suggest against the use of testosterone as monotherapy for patients with } \\
\text { erectile dysfunction and hypogonadism }\end{array}$ & $\begin{array}{r}\text { Conditional } \\
\text { recommendation, low } \\
\text { levels of certainty in } \\
\text { evidence }\end{array}$ \\
\hline $\begin{array}{l}\text { 4. Among patients with erectile dysfunction, does increasing physical activity improve erectile } \\
\text { function compared to usual activity? }\end{array}$ & \begin{tabular}{c} 
Conditional \\
patients with erectile dysfunction \\
\hline \multicolumn{2}{|l|}{ re suggest increasing physical activity, rather than usual activity, among } \\
levels of certainty in \\
evidence
\end{tabular} \\
\hline $\begin{array}{l}\text { 5. Among patients with post-prostatectomy erectile dysfunction, should penile rehabilitation } \\
\text { with scheduled PDE5 inhibitor be used over no intervention? }\end{array}$ \\
\hline $\begin{array}{l}\text { We suggest against the use of scheduled PDE5 inhibitor for penile } \\
\text { rehabilitation among patients with post-prostatectomy erectile dysfunction } \\
\end{array}$ & $\begin{array}{c}\text { Conditional } \\
\text { recommendation, low }\end{array}$ \\
\end{tabular}

